was noticed till April, 1894, when he had violent attacks of headache on the vertex and left side of the head, coming on almost daily and obliging him to cease work; this lasted till he end of May, when he resumed work, but noticed that his mouth was drawn to the right. In August, 1894, he was again seized with a burning pain in the left side of the face, but managed to work till Sept. 1st, 1894, when his left eye became inflamed; he was then treated for a month at the Ophthalmic Hospital, Moorfields, and finally had the eye renoved. Early in January, 1895, he had attacks of vomiting eoming on about half an hour after food, which recurred for three months and were accompanied by severe headaches, while about this time he noticed soreness of the Jeft side of the mouth, cheek, and tongue. For the last year his speech had been rather defective. At this time the patient was a man of muddy complexion, with grey hair, and arcus senilis; he was rather anæmic and wasted; there were a few pigmented scars on the legs, but none elsewhere. His arteries were tortuous and fibroid; the pulse was normal and regular. He had severe burning headache above the left zygoma, then there was great tenderness to pressure. His mind was clear, though torpid, and he had no giddiness. His speech was thick and blurred, though distinguishable. The left eye had been removed, but the right had no paralysis, and its pupil reacted to light and accommodation; the fundus was normal. There was slight nystagmus on Jooking to the right. There was paralysis of all the muscles supplied by the left facial nerve, except for slight movements of the eyelids and forehead when the opposite side moved. The whole region supplied by the left trigeminal merve was completely anæsthetic, and there was also paralysis and wasting of the left temporal and masseter muscles and apparantly also of the external pterygoid, for when the mouth opened the chin deviated to the left. The skin of the face was rather glossy on the left side, but there was no loss of hair or other trophic change. There was no loss of hearing, smell, or taste on either side. The left vocal cord lay in the cadaveric position, and did not move on articuFation; the uvula was drawn to the right, and the arch of the soft palate relaxed on the left, with diminished palatal reflex. There was no paralysis or wasting of the tongue, which was protruded straight forward, but he complained of great soreness on its left side and toothache on the same side. The movements were good in the head and neck. The grasp was slightly less on the right side, and there were increased tendon reflexes in both arms, but no sensory or motor changes. The gait was rather weak and stiff; there was no weakness of the legs, but the knee-jerks were abnormally active, and ankle-clonus could be obtained. There was no affection of the bladder or rectum. There was nothing abormal in the chest or abdomen, except that the liver was slightly enlarged. The urine was of sp. gr. 1008 and neutral. It contained no albumen or sugar. There was a slight deficit of urates. The patient was given a mixture containing mercury and iodide of potassium, but his headache and malaise continued till April 25th, when he began to have diffsulty in swallowing; this improved in a few days, but returned, till finally an attempt to swallow produced choking fits and rejection of the liquid food, so that a catheter had to be used for feeding. On May 7 th there was some loss of sensibility to heat and cold in the right arm and leg, and a week later he began to lose power in this side. The choking: fits returned independently of food, and he occasionally soughed up a mucoid expectoration. There were detected signs of bronchitis and broncho-pneumonia at the base of the right lung, and the temperature, which previously had been normal, rose to $101 \cdot 6^{\circ} \mathrm{F}$., to drop next day to normal. These fits of choking increased in frequency and exhausted the patient, who was already very weak from the slight amount of nourishment he was able to swallow, till he died on May 17th, about six weeks after his admission. At the necropsy, made by Dr. Hebb, the dura mater was found to be non-adherent to the brain, except over the left lobe of the cerebellum, and for about an inch in the middle of the third Jeft temporo-sphenoidal convolution, where it was firmly attached, and the subjacent cortex was atrophied. The inner wall of the straight sinus was thickened and felt like a solid cord, though the lumen was still patent. In the left cerebellar peduncle, stretching as far as the middle line of the pons, was an elongated gumma measuring $1 \frac{1}{2}$ in. by $\frac{1}{2}$ in., firm, gray, and glistening, with central fibro-caseation. The pons was larger than natural and felt boggy. The arteries at the base were normal. The left Gasserian ganglion was trophied, so that it was about half as large as the right, but there was no thickening around it; the root and divisions of the trigeminal were all thin and atrophied. The left half of the medulla was much atrophied and about three-quarters the size of the right, and there was some wasting of the facial and vagus nerves. There were no changes to be seen in the fresh cord. There was very marked wasting of the intrinsic muscles of the larynx on the left side; also there was well-marked syphilitic aortitis. The lower lobes of both lungs were pneumonic and friable, except the lower part of the right lung, where there was a mass of pigmented fibrous tissue, the superjacent pleura being thickened, white, and opaque-evidently the remains of a syphilitic lesion. The rest of the organs were apparently normal.

Remarks by Dr. J. PoRTER PARKINSON.--The diagnosis of this case did not present much difficulty; the paralysiscomplete of the trigeminal nerve and partial of the facial nerve-indicated a lesion in the position or neighbour. hood of the nucleus of the trigeminal nerve, and when the rightsided hemiplegia became marked this was certain. The evidence of previous syphilis pointed to the lesion being due to a syphilitic lesion, while the absence of involvement of other cranial nerves, such as the auditory nerve, made one suspect the lesion to be in the brain substance. The gradual onset of bulbar symptoms was evidently due to extension of the lesion downwards. The case from the first symptom lasted thirteen months, and it is interesting to note that it began by pain referred to the extremity of the malar twig of the trigeminal nerve. The gumma appeared to press equally on the reticular formation and the pyramidal bundle of the pons, and the loss of sensibility to heat and cold on the right side may have been due to pressure on the former. It would be useless to try to make any deductions from an isolated case but unilateral tumours in this situation are sufficiently infrequent to make it worth while placing each one on record.

\section{WEST HERTS INFIRMARY.}

CASE OF PERFORATING GASTRIC ULCER; LAPAROTOMY; DEATH ; NECROPSY

(Under the care of Dr. Russelu STEELE.)

THIs case is one of the kind to which special attention has been frequently drawn in the columns of THE LANCET by reason of the great importance of such cases as an addition to our somewhat imperfect knowledge of the subject. The complication which apparently proved fatal, that of the escape of stomach contents through a second ulcer in the posterior wall, is one which need not be in any way regarded as weighing against operation; it is very rare to meet with more than one ulcer. Then, again, it has been calculated that of ulcers on the posterior wall only 2 per cent. perforate, as opposed to 85 per cent. of those situated on the anterior wall. The type of patient appears to have been typical of that recognised as characteristic of the sufferer from gastric ulcer. The promptitude of diagnosis and management of the case were all that could be desired, and we can only regret that the unusual, almost unknown, complication prevented the attainment of the hoped-for success. For the notes of this case we are indebted to Dr. William Martin, house surgeon.

A female patient, unmarried, aged twenty-one years, was admitted to the West Herts Infirmary, Hemel Hempstead, at 9 P.M. on Nov. 17th, 1894, suffering from great shock. She was too ill to go very closely into the history, but the following points were elicited. For about six months she had been troubled with dyspepsia, which had been much worse fot about two months. She had severe pain in the "stomach and back" on taking food. The pain, which came on soon after taking anything, was relieved by pomiting. For some time she had vomited after every meal when any attempt was made to take solid food. The pain, although aggravated by ingestion of food, was often felt very severely, quite independent of this, especially in the back. She had never to her knowledge vomited blood or passed any by the bowel. Menstruation began at nineteen years of age, was regular for a short time, but had been absent for six months. On Nov. 17th she was about her ordinary work as a narsemaid during the day. She had dinner at 2 P.M., consisting of salt beef and potatoes, but took very little. She had nothing else by the mouth after this. At 5.30 P.M. she mas in her room doing her hair, when, as ske was stretching her 
arms up, she suddenly felt intense, agonising pain in the abdomen, and was just able to throw herself on her bed, where she was found soon afterwards almost insensible, and Dr. Russell Steele was sent for. He found her at 6 P.M. lying "curled up" on her side in bed, with all the signs of great shock. She had vomited several times before his arrival, and did so again while he was with her. The vomited matter, all of which was inspected, showed no trace of blood and seemed to consist only of partially digested food and mucus. The presence of a perforating gastric ulcer was suspected. A hypodermic injection of morphine was given, and when the patient had rallied somewhat she was carefully removed to the infirmary, a distance of about 500 yards, and admitted at 9 P.M. On admission, although still greatly collapsed, the patient was beginning to rally. She lay quite still npon her back with the thighs flexed and without complaining of much pain. The abdominal wall was tense from contraction of the muscles, but there was no obvious distension. The movements were very slight, the respiration being almost entirely thoracic. On palpation there was some general tenderness, but distinct pain on pressure was complained of below and to the left of the nmbilicus. There was no marked tenderness in the epigastric and left hypochondriac regions. The percussion note was dull at the lower part of the abdomen, but tympanitic in the lumbar regions and elsewhere. The liver dulness was normal. An indistinct sense of fluctuation was made out below the umbilicus. A catheter was passed into the bladder, and a few ounces of quite healthy urine were drawn off. Nothing abnormal was found on rectal or vaginal examination. An exploratory operation was strongly advised, but the relatives wonld not consent without having a night to think the matter over. The patient's general condition improred somewhat up to 12 midnight, after which she gradually grew worse. Nutrient and stimulating enemata were administered during the night. There was no vomiting after admission, and no passage of motion or flatus by the bowel. At 11 A.M. Mr. F. C. Fisher saw the case in consultation with Dr. Steele. At this time the abrlomen was slightly distended, tenderness was more general, a distinct fluctuation wave could be made out, and there was dulness on percussion in the lumbar region on each side. The patient was still in fair condition; the temperature was $99^{\circ} \mathrm{F}$. and the pulse 125. The consent of the friends was obtained, and at 12:30 P.M., nineteen hours from the onset of symptoms, she was put under ether by Dr. Hubbard, and Dr. Steele, assisted by Mr. Fisher, opened the abdomen. A median incision was made below the umbilicus midway between it and the pubes. On dividing the peritoneum a considerable quantity of turbid fluid with large flakes of lymph gushed out, and the patient became much collapsed. One pint of normal saline solution was injected into the right median cephalic vein with speedy and obvious benefit. A rapid and careful examination of the vermiform appendix and cæcum as well as the pelvic viscera revealed nothing wrong. The wound was then temporarily closed with a sponge and a median incision made between the ensiform cartilage and the umbilicus. The stomach presented in the wound. At first nothing wrong could be made out, but, on passing the hand over to the left under the costal margin the examining fingers canght in a large rent in the anterior wall. It was impossible to bring the perforation to the wound, so an incision was made at right angles, extending to the left costal margin across the fibres of the rectus muscle. By this means a fair exposure was obtained. The stomach was not washed out, and the edges of the ulcer were not parred. The perforation, which was about the size of a florin, was carefully closed with fine silk sutures after Lembert's method, some difficulty being experienced in introducing those on the extreme left. A second row of sutures was introduced with a hold further back in order to take tension off the main line of suture. A glass drainage-tube was then put into the pelvis through the lower wound to facilitate the flow of fluid, and the whole carity of the abromen was carefully and systematically flushed, beginning at the site of the sutured ulcer. The solution used was boiler water containing a drachm of sodium chloride to the pint and at a temperature of $108^{\circ}$, the irrigation being continned until it returned clear. The wounds were then clored, an indiarubber drainage-tube being passed down to the region of the perforation through the outer end of the rectangular incision, and the Keith's tube left in the lower wound. The ordinary dressings were applied. The operation had occupied nearly an hour and a half. At its completion the patient was greatly collapsed. One pint and a half of normal saline fluid was passed into the left median cephalic vein, with distinct but temporary improvement. All the usual remedlies for shock were assiduously employed, with the result that the patient completely regained consciousness. She was able to recoonise and talk to her friends. During this time she complained of much pain in the back. She, howerer, gradually sank, and, in spite of all that could be done, died at 5.30 P.M.- -three hours and a half from the completion of the operation, and twenty-four hours after the perforation. A partial postmortem examination was made twenty-four hours after death. There were the usual signs of acute diffuse peritonitis. On dividing the great omentum at its attachment to the lower border of the stomach a quantity of fluid, which seemed to consist of inflammatory exudation and partially-digested food, was found. At first it was not clear where this could come from; but on carefully raising the stomach a second ulcer, about the size of a sixpenny-piece, was found, which had perforated owing to the adhesions which had bound it to. the pancreas having given way for the greater part of the circumference of the ulcer. As seen, the stomach wall was still adherent to the pancreas for a short distance along the upper margin of the perforation. The stomach and pancreas were carefully removed. On testing the sutured nlcer it was found to be perfectly watertight. The ulcers were almost exactly opposite to each other, the posterior being a little to the right of the anterior. Both were situated almost vertically below the cardiac orifice and about midway between the lesser and greater curvatures of the stomach.

Remarks by Dr. STEELE.-Although unsuccessful, this case appeared to me to be of particular interest and worthy of publication for the following reasons: 1. Although such extensive ulceration was discovered, the patient had never been so seriously ill as to consult a medical man, and, according to her statements and those of her friends, there had never been hæmatemesis or melæna at any time. 2. The ill-defined nature of the physical signs on admission, the fact of the chief signs on examination pointing to some lesion in the lower part of the abdomen led me, in spite of the history of gastric trouble, to explore this region first. 3. A great point of interest and importance was the presence of another ulcer on the posterior wall of the stomach. I think it probable that the adhesion between it and the pancreas may have been broken down during the necessary manipulations for suturing the ulcer on the anterior wall. It was a matter for regret that permission to operate could not be obtained at an earlier period, although the presence of an undiscorered perforation on the posterior wall of the stomach would have caused a fatal result in any case. In conclusion, I wish to tender my grateful thanks to my colleague, Mr. Fisher, and to Dr. William Martin, my house surgeon, for their valuable assistance, as also to my partner, Dr. Hubbard, who kindly administered the anæsthetic.

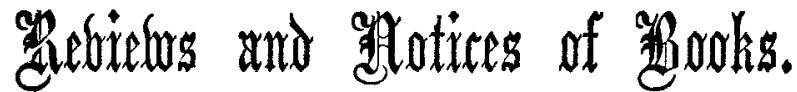

A System of Surgery. Edited by FREDERICK TREves, F.R.C.S., Surgeon to the London Hospital. Vol. I. With two coloured plates and 463 illustrations. Cassell and Company, Limited, London, Paris, and Melbourne. 1895.

\section{[FIRST NotICE.]}

THe appearance of a new text-book of surgery is, or should be, an important event in medical literature, and the volume before us is a notable addition to the standard works on surgery. The whole work will appear in two volumes, of which only the first has at present been published. This is a handsome large octavo volume of over 1100 pages of text, well printed, copiously illustrated, and presenting an attractive appearance. The publishers are to be heartily congratulated on the way in which their share of the work has been done.

"A System of Surgery" is the work of twenty-five writers, with two exceptions surgeons, who have been well selected from among the acknowledged representatives of the present phase of surgical teaching. The twenty-three surgical authors 